\title{
Return-based Style Analysis in Australian Funds
}

\author{
Robert W. Faff \\ University of Queensland, Australia \\ Philip Gharghori \\ Monash University, Australia \\ Bonnie H.I. Ip \\ BPM Financial Modelling, Australia \\ Annette Nguyen* \\ Deakin University, Australia
}

This study applies return-based style analysis to a sample of Australian managed and superannuation funds, seeking to compare their asset allocation strategies across different style groups. Style analysis is performed using a rolling window estimation technique. As expected, riskier fund classes are more exposed to the riskier benchmarks. Further, differences in institutional and legal settings lead the managers of managed and superannuation funds to invest differently, with the latter employing a more conservative investment strategy despite having longer investment horizons. (JEL: G11, G15)

Keywords: Style analysis, managed funds, superannuation funds, fund performance

\section{Introduction}

In this paper, using Australia as an experimental setting, the strategy and performance of managed funds is compared with that of superannuation

\footnotetext{
* We thank two anonymous referees and the editor for helpful comments, and John Watson for assistance with the data. The financial support provided by the Australian Centre of Financial Studies is gratefully acknowledged.
}

(Multinational Finance Journal, 2012, vol. 16, no. 3/4, pp. 155-188)

(C) Multinational Finance Society, a nonprofit corporation. All rights reserved.

DOI: $10.17578 / 16-3 / 4-1$ 
funds. ${ }^{1}$ More specifically, the paper applies a time-varying return-based style analysis seeking to compare the asset allocation strategies adopted by managers of managed and superannuation funds. To the best of our knowledge, it is the first to perform this analysis in Australia and more broadly, it is the first to explicitly compare managed funds and superannuation funds in Australia and the second to do so internationally. ${ }^{2}$ The study has very important practical implications because most investors who invest in managed funds also have their money in superannuation while the reverse does not hold. If the findings indicate that managed funds underperform superannuation funds, then this implies that investors should contribute as much as possible to their superannuation because the performance of managed fund managers do not justify their fees.

The Australian funds management industry is one of the largest and fastest growing in the world. Total assets under management have increased 460 per cent since 1992, with a compound annual growth rate of 12.2 per cent. Conservative industry estimates forecast this figure will reach $A \$ 2.5$ trillion by $2015 .^{3}$ The continued strong growth of the funds management sector is underpinned by Australia's mandatory retirement income system known as the superannuation guarantee levy where employers are required to make contributions equivalent to nine per cent of the employees' salary into a superannuation fund on behalf of the employees. In addition, the Australian market, with a strong and flexible economy, a sophisticated investor base and a world class regulatory system is an ideal environment for a rapid expansion of funds under management. Unlike most developed economies, the Australian economy has continued to perform well following the financial crisis and despite greater global financial market integration (Charitou, Makris and Nishiotis, 2006), Australian funds under management are already above pre-crisis levels.

Given its magnitude, the investment style and performance of the Australian managed fund industry has been researched extensively over

1. Australian managed funds are similar to mutual funds in the US whereas Australian superannuation funds are akin to pension funds in the US.

2. Del Guercio and Tkac (2002) compare mutual funds and pension funds in a US setting; however, their focus is on asset flows and performance. This paper evaluates the investment decisions of managed fund and superannuation fund managers using style analysis.

3. Department of Innovation Industry, Science and Research, Managed Funds in Australia, 2008. 
the past 30 years. Early studies by Bird, Chin and McCrae (1983), Robson (1986), Vos, Brown and Christie (1995), Sinclair (1990), Hallahan and Faff (1999) and Holmes and Faff (2000) find evidence of poor fund performance. More recently, Holmes and Faff (2008) provide a comprehensive investigation on the market timing and stock selection skills of Australian fund managers during up and down markets using conditional models proposed by Ferson and Schadt (1996). Their results indicate that managers exhibit positive selectivity and negative market timing ability for the majority of funds. Faff, Gallagher and Wu (2005) focus their attention on the asset allocation strategies of Australian fund managers. They find that active managers have been unable to add value to investors through tactical asset allocation, which leads the authors to question the role of dynamic asset allocation decisions made by portfolio managers and the reasons why they fail to deliver superior returns.

Previous studies often group superannuation funds and funds actively invested through investment managers (managed funds) in the same category. In fact, the legal and institutional settings of these two types of funds differ considerably, which may lead the funds to pursue different investment strategies. As superannuation is money invested for retirement, members generally cannot withdraw funds out of their superannuation until they reach retirement age. Thus, the money flows of superannuation funds are not closely linked with the performance of the market. This is in contrast to managed funds where managers often experience inflows (outflows) during a strong (weak) market. In addition, since investors of managed funds can contribute and withdraw their money voluntarily, there are good reasons to expect the managers of these funds to be more concerned with their ratings and consequently, they are more likely to actively manage their portfolios. Finally, managers of superannuation funds face a longer investment horizon compared to managed funds. This implies that managers of superannuation funds can afford to take on more risk(s) so that over the long term, higher risk will yield higher returns. However, the counter argument is that the first priority of superannuation investment is to protect the members' retirement benefits, which may lead managers to be more passive and allocate a lower proportion of their portfolio to risky investments.

Regardless of their differences, the market for both superannuation and managed funds are quite substantial. As at 30 June 2011, total assets invested under managed funds amount to A $\$ 800$ billion dollars, for 
superannuation funds, this figure is $\mathrm{A} \$ 1.3$ trillion dollars. ${ }^{4}$ Given the size and importance of the industry, it is crucial to analyse the strategies that superannuation and managed fund managers adopt and examine whether differences in legal and institutional frameworks lead to a variation in managers' investment philosophy. This is the core research goal of the paper.

The study employs a return-based style analysis (RBSA) developed by Sharpe $(1988,1992)$ to assess the asset allocation strategies of managed and superannuation fund managers. Recent examples that employ RBSA include Domian and Reichenstein (2009), Bodson, Coen and Hubner (2010) and Xiong, Ibbotson, Idzorek and Chen (2010). While there are other approaches to examine the fund's investment style, such as the portfolio-composition-based approach and data envelopment analysis (Alexakis and Tsolas, 2011), the RBSA approach works better with multi-sector funds, which invest across a number of asset classes. According to Dor and Jagannathan (2002), managers of these funds are restricted to buying and holding assets in distinctive asset classes and they typically do not have access to leverage and short selling. Their goal is to meet or exceed the returns of the benchmark, which results in high correlations between the returns generated by the managers and those on the benchmark. Thus, one can capture changes in investment styles over time by observing the extent to which the portfolio returns correlate with each of the style indices. This is clearly different to hedge funds where managers are typically given an absolute return target regardless of the performance of the market and where they can employ alternative trading strategies such as the use of financial derivatives, short-selling and leverage.

As expected, the results indicate that riskier fund classes have greater exposure to riskier benchmarks. Despite having longer investment horizons, superannuation fund managers adopt a much more conservative investment strategy compared to managed funds. This suggests that superannuation fund managers are more interested in protecting their capital than generating superior returns. This has very important implications for policy makers as in addition to protecting the members' capital, superannuation funds need to generate enough income to fund members' retirements. Dunn, Francis and Hall (2009) document that based on a nine per cent contribution, the median projected annuity stream in retirement for the representative investor is

4. Australian Bureau of Statistics, cat, No 5655.0, June 2011. 
$\$ A 39,000$ per year. This figure increases to $\$ A 63,000$ if the portfolio is 50 per cent levered. The paper's findings provide policy makers an opportunity to investigate whether the investment strategies adopted by superannuation fund managers are "too conservative" given that they have very long investment horizons.

With regard to performance, managed funds tend to outperform superannuation funds in the less risky fund categories, while there is some evidence of better performance by superannuation fund managers in the most aggressive fund category. Finally, the study documents that in fund groups where RBSA has strong explanatory power within sample (low tracking error), it also exerts a higher degree of predictability out of sample (low forecast error). This indicates that the RBSA technique works quite consistently.

The remainder of the paper is organised as follows. The next section summarises the existing literature, discusses the institutional framework of managed and superannuation funds, and reviews style analysis. Section III describes the data and methods. Section IV reports the findings and section $\mathrm{V}$ concludes.

\section{Institutional Framework and Literature Review}

\section{A. Superannuation Funds and Managed Funds}

Superannuation funds buy and sell assets on their own account while managed funds do so for a fee on behalf of their clients. Superannuation funds are regulated under the Superannuation Industry (Supervision) Act 1993 (SIS Act), which is administered by the Australian Prudential Regulation Authority. The SIS Act requires the trustee when making decisions to consider not only the risk and returns but also the diversification and liquidity aspects of the investments. In contrast, managed funds are regulated under the Corporations Act 2001, which does not specifically outline any requirement to which managers have to strictly adhere when formulating their investment strategy. Superannuation funds are formed as a trust with the trustee responsible for administering the fund within the trust. Therefore, it is reasonable to expect superannuation funds to attract higher fees compared to managed funds, as in addition to paying the investment managers, members of superannuation funds have to pay the trustee(s). The tax regimes on these two types of funds also differ. New funds flowing into 
superannuation funds from members are taxed at a rate of 15 per cent prior to investment whereas with managed funds, investors are taxed at their marginal rate based on the return the fund generates. Finally, unlike managed funds where investors can redeem their money at any time, members of superannuation funds generally cannot withdraw their money until they reach their retirement age. This indicates that managers of superannuation funds tend to face much longer investment horizons and less volatile money flows compared to managed funds. This is pertinent given that money flows and investment horizons are characteristics that are known to have a strong influence on the investment decisions of fund managers.

\section{B. Return-Based Style Analysis}

Sharpe's $(1988,1992)$ return-based style analysis (RBSA) can be thought of as a special case of the generic factor model, which involves regressing the fund's historical return against the returns of a set of passively constructed reference portfolios to determine the fund's exposure to each of the reference portfolios. The reference portfolios are known as the style benchmarks. The model can be written as:

$$
R_{t}^{\text {fund }}=\beta_{1} \cdot R_{t}^{\text {index } 1}+\beta_{2} \cdot R_{t}^{\text {index } 2}+\ldots+\beta_{k} \cdot R_{t}^{\text {indexK }}+\varepsilon_{t}^{\text {fund }}
$$

where $R_{t}^{\text {fund }}=$ return of the fund in month $t, R_{t}^{\text {indexi }}=$ return on the style index $i$ in month $t, \beta_{i}=$ exposure to style index $i$, and $\varepsilon_{t}^{\text {fund }}=$ fund specific error term. The objective of style analysis is to select a set of asset class exposures that minimises the variance of the error term $\left(\varepsilon_{t}^{\text {fund }}\right)$, i.e. the difference between the actual return on the fund $\left(R_{t}^{\text {fund }}\right)$ and that of a passive portfolio of the same style (Sharpe, 1992), and to infer as much as possible about the fund's exposures to variations in the returns of the asset classes.

Sharpe $(1988,1992)$ has identified three alternative forms of RBSA, namely weak, semi-strong and strong form. If no constraint is imposed on the coefficients, this is referred to as weak form. In semi-strong form, the portfolio constraint is imposed, which requires the weights allocated to each of the style benchmarks to sum to one.

$$
\sum_{i=1}^{K} \beta_{i}=1
$$


Finally, strong form requires that all estimated portfolio holdings should be long positions. This does not mean that short sales in general are prohibited, but rather short sales in style categories are not allowed. That is,

$$
\beta_{i} \geq 0, i=1, \ldots, K
$$

A serious drawback of the above model is that it unrealistically assumes that the portfolios' exposures to the asset classes remain constant over the length of the entire estimation period, which could be up to 15 years or more. Since fund managers dynamically change the portfolio weights over time (Grinblatt, Titman and Wermers, 1995; and Ferson and Schadt, 1996), it is unreasonable to apply a model with time-invariant betas to actual funds' data. Indeed, studies by Kim, Shukla and Tomas (2000) and Chan, Chen and Lakonishok (2002) document plausible asset relocations by portfolio managers.

To overcome the inefficiency of static style analysis, a rolling window regression is employed to track the changes in fund style over time (Atkinson and Choi, 2001; Buetow, Johnson and Runkle, 2000), where exposures (betas) are estimated over windows (sub-samples) according to equation (1). Since style tends to 'drift' over time, the average weights may not be reliable at any particular point in time. However, the rolling window regression is based on the assumption that the style exposures are constant over the shorter sample window, which is usually 36 months, as it is recognised to be "short enough to capture considerable style movements, but long enough to avoid excessive 'noise' in the data" (Lucas and Riepe, 1996). This approach implicitly introduces time-varying exposures to style analysis.

\section{Return-Based Style Analysis in Australia}

Although the managed fund industry has been heavily researched in Australia, studies which utilise RBSA to examine the investment strategies of Australian fund managers are sparse. Based on a rolling window return-based analysis, Holmes and Faff $(2007,2008)$ find that style drift is evident in Australian multi-sector managed funds with some funds exhibiting a major style change. In addition, they observe that style drift is positively related to selectivity performance only in weak markets. Phoon, Watson and Wickramanayake (2008) investigate the style and asset allocation strategies of 50 listed managed funds by approximating the confidence intervals for the estimated style weights. 
Their evidence suggests that reliable style weights can be constructed using monthly data and that Sharpe style weights together with the confidence intervals provide valuable insights into the asset allocations decisions adopted by fund managers. Allen, Phoon, Watson and Wickramanayake (2010) evaluate the extent to which Australian multi-sector managed funds are misclassified. They find that a significant proportion of funds in Australia are misclassified, however this is not the reason why these funds underperform. The use of RBSA is also extended to socially responsible investments (SRI). Gerrans, Kristoffersen and Clark-Murphy (2004) find that Australian SRI funds do no exhibit a distinctive style.

In summary, academic studies which employ RBSA using Australian data are limited. Given the size and importance of the managed and superannuation fund industry, there is a need to investigate whether RBSA can improve investors' understanding on the asset allocation strategies adopted by managers. This type research can also draw meaningful insights on whether differences in institutional and legal settings lead the managers of managed funds and superannuation funds to invest differently.

\section{Data and Methods}

\section{A. Data}

The data consists of monthly returns for 447 managed funds and 453 superannuation funds in Australia for the period January 1990 to December 2011. To enable reliable inference from the RBSA, each fund in the sample is required to have at least 72 months of continuous monthly return information available. ${ }^{5}$ The source of these data is the survivorship bias-free Morningstar Direct fund database. Returns obtained from this database are calculated after management fees. The funds are divided into 5 categories: conservative, moderate, balanced, growth and aggressive. The sample consists of multi-sector managed and superannuation funds, which invest in multiple asset classes. Morningstar defines a fund as multi-sector if it has exposure to an

5. These data are not subject to any material survivorship bias, since funds which cease to exist at December 2011 but meet the minimum data criterion of 72 months are included in the analysis. 
income or growth sector and at least one other growth sector, except where cash is involved. When cash exposure is greater than 30 per cent and the fund is exposed to one growth sector, it is also categorised as multi-sector. ${ }^{6}$

The success of RBSA depends on the correct specification of style benchmark indices. Given the inequality constraint in equation (3), standard assumptions regarding the distribution of the exposure coefficients do not apply and hence, the significance of the coefficients cannot easily be obtained by any statistical modelling. It is therefore difficult to judge whether the mix of asset classes chosen as style benchmarks are appropriate. However, Sharpe (1992) outlines a number of desirable characteristics that researchers should have in mind when choosing the asset mix. Specifically, asset classes should be exhaustive and include as many securities as possible. Second, they should be mutually exclusive and have low correlation with each other. Based on these criteria, the following six indices are adopted as style benchmarks. These benchmarks are first introduced in Faff, Gallagher and Wu (2005) and later employed in Holmes and Faff (2007). They are (a) Australian Equity (AEQ): Australian DataStream (DS) Market Index; (b) Australian Fixed Interest (AFI): UBS Composite All Maturities Index; (c) International Equity (IEQ): MSCI World Ex Australian Index; (d) Listed Property (LP): ASX Property Trust Index; (e) Overseas Fixed Interest (OFI): WD Citigroup G7 All Maturities Index; (f) Cash: Reserve Bank of Australia 90 day BAB Index. The data for these indices are obtained from DataStream.

\section{B. Methods}

The paper applies the strong-form portfolio version of RBSA. The reason is superannuation and managed funds cannot feasibly maintain short positions in entire asset classes. Sharpe (1992) has adopted a method to minimise the variance of the error term in equation (1) for determining fund exposures. In the spirit of Ter Horst, de Roon and Nijman (2004), the original RBSA model is modified by adding an intercept term to equation (1). In this case, minimising the sum of squared differences is mathematically equivalent to minimising the variance of the error term without an intercept and it results in identical

6. Morningstar Research Pty Ltd, Classification Policy Australian Investments, October 2007 (http://www.morningstar.com.au/productpages/classification_policy_06.pdf). 
parameter estimates. Further, minimising the sum of squared differences is more consistent with standard econometric techniques and it also allows for the estimation of alphas.

In this analysis, the beta exposures on the six benchmark indices and the intercepts are obtained by minimising the sum of squared differences of the tracking errors, which is defined as the difference between the actual fund return and the predicted fund return derived from the style exposures. It then results in a set of style weights and alphas for each fund. Thus, the following equation is estimated:

$$
R_{t}^{\text {fund }}=\alpha+\beta_{1} \cdot R_{t}^{\text {index } 1}+\beta_{2} \cdot R_{t}^{\text {index } 2}+\ldots+\beta_{k} \cdot R_{t}^{\text {indexK }}+\varepsilon_{t}^{\text {fund }}
$$

To allow for time-varying style, a 36-month rolling window is employed to create an evolving set of estimations for the style weights over the sample period. Alphas and betas will be obtained for every window and their average values are calculated. Although the 36-month rolling window has been widely used in previous research (Atkinson and Choi, 2001; Buetow et al., 2000; and Papadamou and Siriopoulos, 2004), the choice of this estimation period is still somewhat arbitrary. To test the robustness, the analysis is repeated using 24- and 48-month rolling windows.

The intercept alpha in equation (4) represents the expected excess return of the fund relative to the benchmark. Ter Horst et al. (2004) argue that the intercept alpha coincides with the Jensen (1968) measure if one of the assets is a risk-free deposit and the positivity constraints are valid. This is especially true in the sample for this study given the short-sale restriction imposed on managed and superannuation funds, and because one of the benchmark indices is Cash. However, researchers should not make judgement on whether the funds under- or over-perform the benchmark based on the intercept alpha alone. The reason is the risk of the funds may differ from the benchmark. Specifically, if $\operatorname{Var}\left(\varepsilon_{t}\right)>0$, then a positive alpha implies that the fund achieves higher returns by taking on higher risk and therefore should not be preferred to the benchmark. Meanwhile, a negative alpha is not evidence of underperformance if the risk of the fund is lower. Ter Horst et al. (2004) use the Sharpe ratio in addition to the intercept to make inferences on fund performance. Specifically, if the managers attain higher returns through higher risk, then this should lower the Sharpe ratio and vice versa.

To assess the ability of RBSA in forecasting future returns, the 
predicted returns from the style exposures are compared with the actual returns $\left(R_{p, t+1}\right)$, to give forecast errors. The predicted returns are defined as the predicted style exposures times the actual style returns at $t+1$, plus the predicted intercept; and comparisons are made among the forecast errors obtained from the rolling window regressions. The forecast error will be calculated out-of-sample based on the one-step ahead forecast for the $37^{\text {th }}$ monthly return observation (assuming a rolling window of 36 months) for each fund under the two methods. The two distance measures employed to evaluate the forecast performance are the mean absolute deviation (MAD) and the mean squared deviation (MSD):

$$
\begin{aligned}
& M A D_{p}=\frac{1}{T} \sum_{t=0}^{T-1}\left|\hat{\alpha}_{t+1}+R_{t+1}^{\text {indexj }} \hat{\beta}_{p, t+1}-R_{p, t+1}^{\text {fund }}\right| \\
& M S D=\frac{1}{T} \sum_{t=0}^{T-1}\left(\hat{\alpha}_{t+1}+R_{t+1}^{\text {indexj }} \hat{\beta}_{p, t+1}-R_{p, t+1}^{\text {fund }}\right)^{2}
\end{aligned}
$$

where $t=0$ corresponds to the first period with an estimate for the rolling window method. Under the rolling window analysis, $t=0$ will begin in the $37^{\text {th }}$ month due to the rolling window length of 36 months.

\section{Results and Discussion}

\section{A. Sample and Index Characteristics}

Table 1 reports descriptive statistics for the five categories of funds in the Australian sample covering the period January 1990 to December 2011, including sample sizes, average monthly returns, standard deviation of returns, t-statistic of the mean returns, and the highest and lowest monthly return of each of the fund categories. Panel A reports the statistics for managed funds while Panel B reports the same information for superannuation funds.

The summary shows a comparable number of funds within each category for superannuation and managed funds. Except for the aggressive category, managed funds exhibit higher average monthly returns although their standard deviation is higher. The lowest and highest monthly returns within each category reveal a similar picture. 


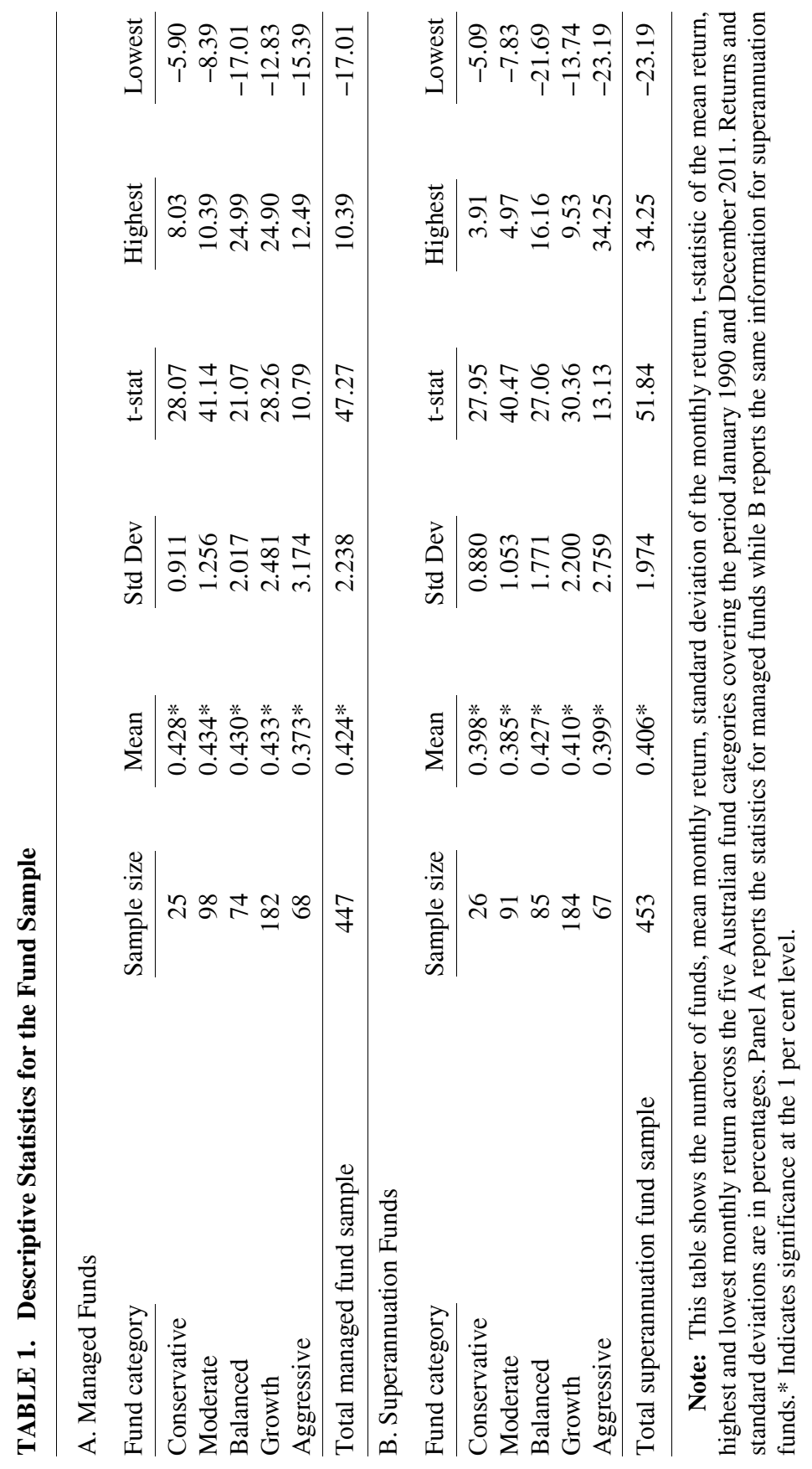


TABLE 2. Descriptive Statistics for the Passive Indices

\begin{tabular}{|c|c|c|c|c|c|c|c|c|}
\hline \multirow{2}{*}{$\begin{array}{l}\text { Asset } \\
\text { Class }\end{array}$} & \multirow[b]{2}{*}{ Mean } & \multirow[b]{2}{*}{ Std Dev } & \multicolumn{6}{|c|}{ Correlations } \\
\hline & & & AEQ & AFI & IEQ & LP & OFI & $\mathrm{CASH}$ \\
\hline$\overline{\mathrm{AEQ}}$ & $0.830 *$ & 3.893 & 1.000 & & & & & \\
\hline AFI & $0.717^{*}$ & 1.173 & 0.112 & 1.000 & & & & \\
\hline IEQ & 0.491 & 4.264 & $0.762 *$ & -0.047 & 1.000 & & & \\
\hline LP & $0.642 *$ & 4.096 & $0.561 *$ & $0.214 *$ & $0.452 *$ & 1.000 & & \\
\hline OFI & $0.502 *$ & 0.915 & -0.017 & $0.647 *$ & -0.061 & 0.120 & 1.000 & \\
\hline CASH & $0.518 *$ & 0.196 & -0.053 & $0.257 *$ & -0.109 & -0.005 & 0.095 & 1.000 \\
\hline
\end{tabular}

Note: This table shows the monthly returns, volatilities and correlations across asset classes for the period January 1990 to December 2011. The mean and standard deviation are reported as percentages. The six style indices examined are: (a) Australian Equity (AEQ): Australian DataStream Market Index; (b) Australian Fixed Interest (AFI): UBS Composite All Maturities Index; (c) International Equity (IEQ): MSCI World Ex Australian Index; (d) Listed Property (LP): ASX Property Trust Index; (e) Overseas Fixed Interest (OFI): WD Citigroup G7 All Maturities Index; (f) Cash: RBA 90 day BAB Index. *Indicates significance at the 5 per cent level.

Except for the aggressive classification, the best performing month within each category for managed funds is higher than for superannuation funds, whilst the worst performing month for managed funds is lower relative to superannuation funds in three out of the five fund groups. Thus, the performance range for managed funds is wider, which is consistent with the higher standard deviations. Meanwhile, the highest and lowest returns across all funds belong to the aggressive superannuation fund group and they are 34.25 per cent per month for the best performing month and -23.19 per cent per month for the worst performing month. This suggests that some funds in this category exhibit quite extreme returns. Finally, the mean returns across different categories of funds do not suggest a strong pattern of increasing returns from the conservative to the aggressive classification. Indeed, aggressive funds are the worst performed of the managed funds groups and close to the worst performed in the superannuation funds groups, which is somewhat contrary to expectations. However, such a feature is reasonable given that the sample includes the financial crisis period where risky investments typically performed very poorly.

Table 2 reports descriptive statistics for the passive indices. Australian Equity (AEQ) is the best performer of the six asset classes, with a mean monthly return of 0.830 per cent. Ranking second is Australian Fixed Interest (AFI) with an average monthly return of 0.717 


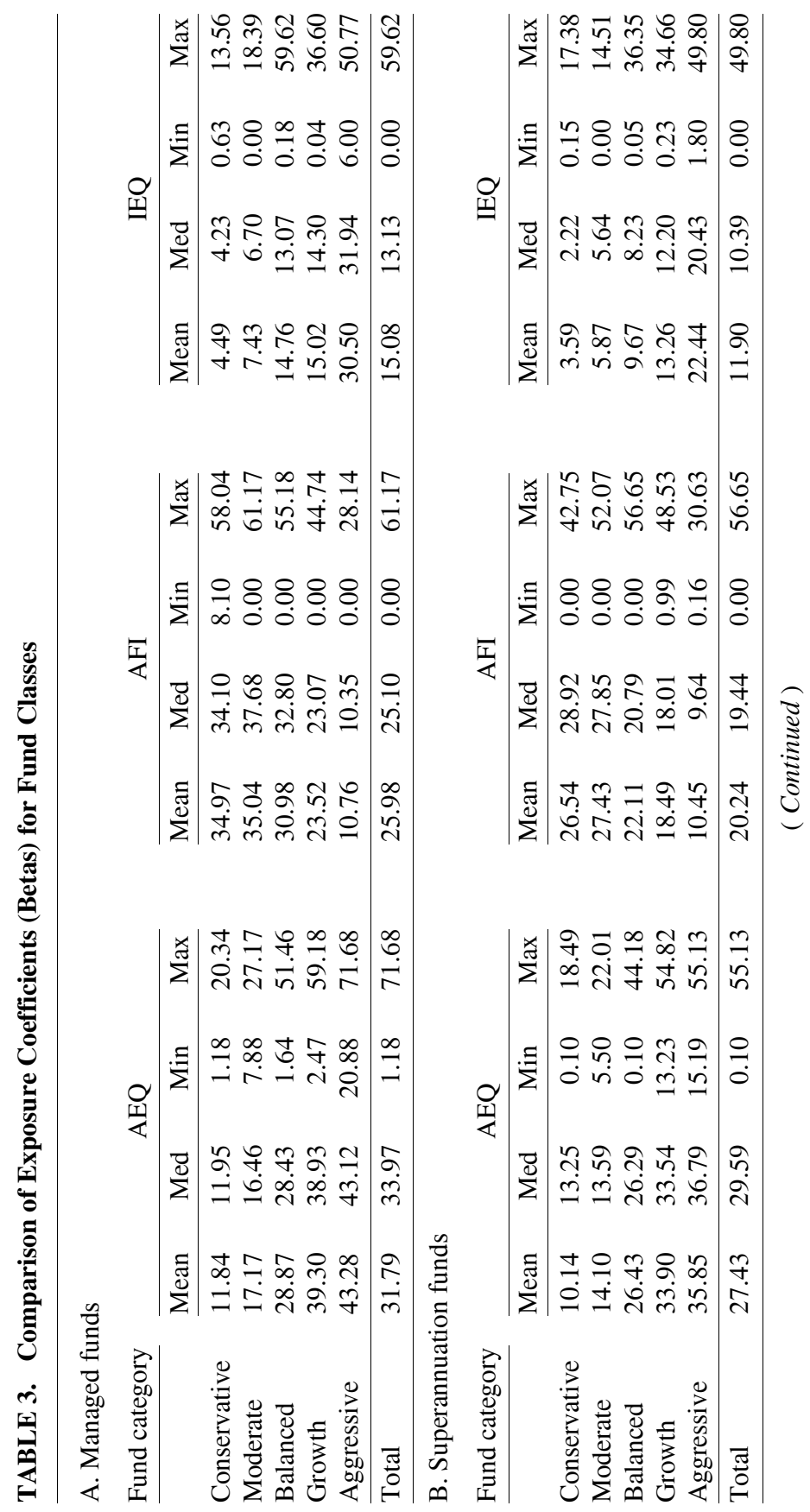




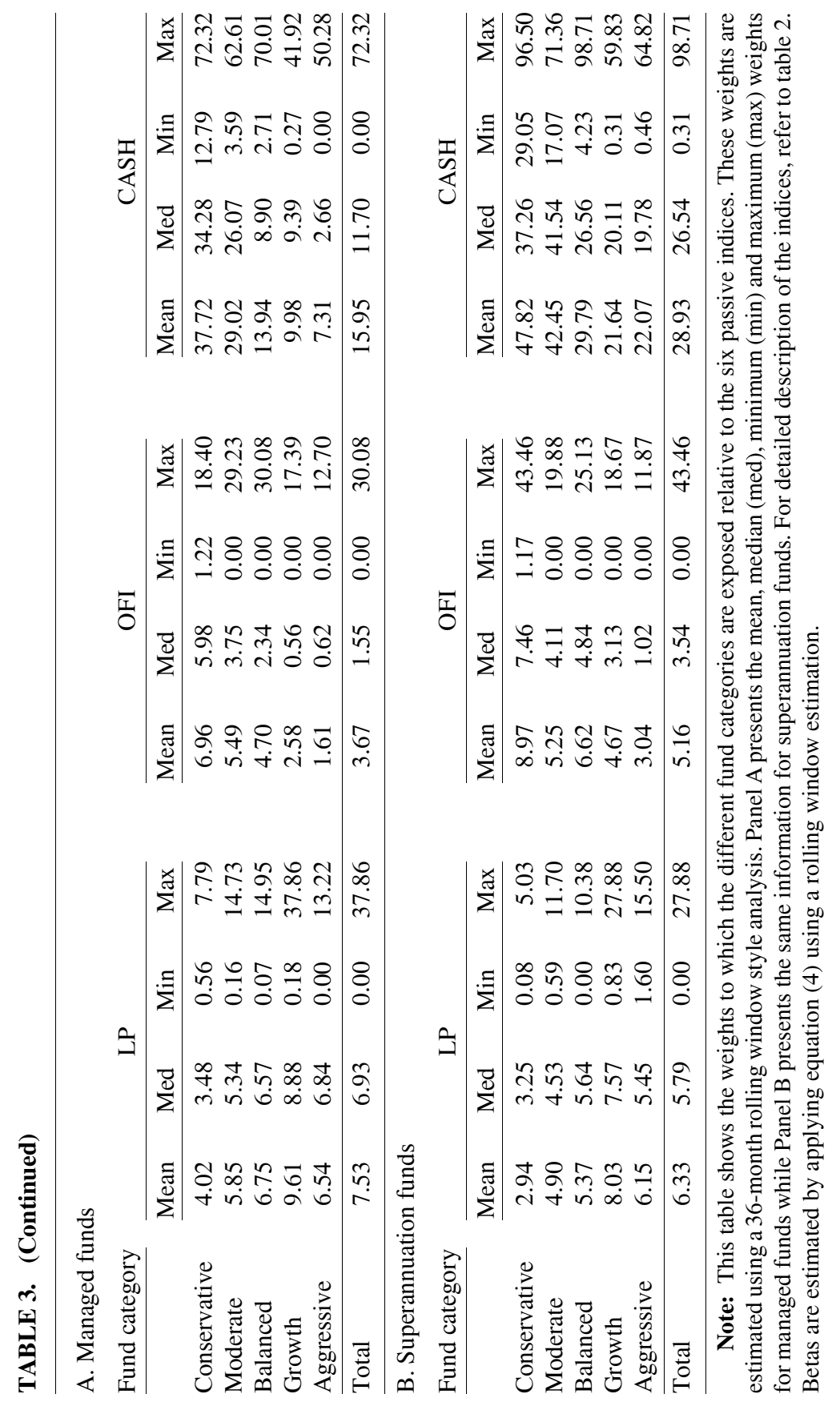


per cent per month. This is consistent with the strong performance of the Australian bond and share market. What is surprising is that Cash does not yield the lowest returns. The return on Cash is higher than both International Equity (IEQ) and Overseas Fixed Interest (OFI) with IEQ being the worst performing asset class, generating a return of 0.491 per cent per month, over the sample period. Among the six asset classes, IEQ is the most volatile, followed by LP and AEQ. With regard to correlations, it is observed that the Australian equity and bond asset classes are strongly related with their corresponding international indices. AEQ and IEQ are the most highly correlated followed by AFI and OFI. This is expected given the impact of market integration.

\section{B. Distribution of Beta Exposures}

Table 3 shows the beta exposures for managed and superannuation funds using the 36-month rolling window estimation. ${ }^{7}$ In addition to reporting the average betas, the table reports the median, minimum and maximum betas for each fund category. The minimum and maximum values indicate that there is a large variation in the distribution of betas for both managed and superannuation funds. The medians are generally quite similar to the means, which suggests that the distributions are symmetric; however, there is some evidence of a right skew in the OFI and Cash exposures in both managed and superannuation funds.

As expected, more aggressive fund classes have higher exposures to risky asset classes such as AEQ and IEQ while less aggressive fund classes have higher exposures to less risky asset classes such as AFI, OFI and Cash. Despite having a much longer investment horizon, superannuation fund managers tend to adopt much more conservative investment strategies compared to managed funds. Across all categories, managers of superannuation funds consistently allocate a smaller proportion of their portfolios to risky indices, namely AEQ, IEQ and LP. In addition, managed funds have higher exposures to AFI, while superannuation funds generally have higher exposure to OFI. Thus, there is some evidence of superannuation fund managers substituting domestic fixed income securities with their corresponding overseas counterparts. Finally, superannuation fund managers invest more

7. The paper also estimates beta exposures using 24- and 48-month rolling windows. However, to conserve space, only the coefficients estimates for the 36-month case are reported, as the results are very similar. Details are available from the authors on request. 
heavily in Cash compared to managed funds, even in the aggressive category where on average, 22 per cent of the portfolio is invested in Cash. This is consistent with the notion that the first priority of superannuation fund managers is to protect members' retirement benefits and Cash is the most suitable investment channel by which managers can preserve capital.

\section{Individual Fund Analysis}

Table 4 reports the mean, minimum and maximum weights for funds with the highest and lowest static R-squared within each category. The static R-squared is calculated using the fund's full time-series of monthly returns. Together with the tracking error, the static R-squared measures the goodness of fit of the model and therefore can be used to assess the extent to which the manager deviates from a specific style and/or the suitability of the benchmarks. What is observed from table 4 is that for funds with the highest R-squared, there is not a large difference between the mean and both the minimum and maximum values. This is in contrast to funds with the lowest $\mathrm{R}$-squared where the minimum and maximum weights of these funds suggest a wide distribution. This pattern is observed for both managed and superannuation funds. In addition, for superannuation funds, funds with the lowest R-squared also exhibit a concentration in one asset class, namely Cash. For example, fund 14182 and fund 15118, on average, allocate about 97 per cent of their portfolio to Cash. To investigate this matter further, the change in style weights over time is plotted for funds with the highest and lowest static R-squared in each fund category. The style weights are obtained from a 36-month rolling window analysis. This is illustrated in figure $1 .^{8}$

For managed funds, it is evident that funds with a high static $\mathrm{R}$-squared display a reasonably constant style mix over the sample period, indicating low variation in beta exposures. Meanwhile, funds with a low static R-squared generally experience a great deal of variability in fund exposures. According to Dor and Jagannathan (2002), a low R-squared suggests either active management or inadequate benchmarks. Looking at the change in style weights over time, it is very unlikely that the observed low R-squared is due to inadequate

8. To conserve space, the change in style weights is only plotted for funds that are in the conservative, balanced and aggressive categories. 


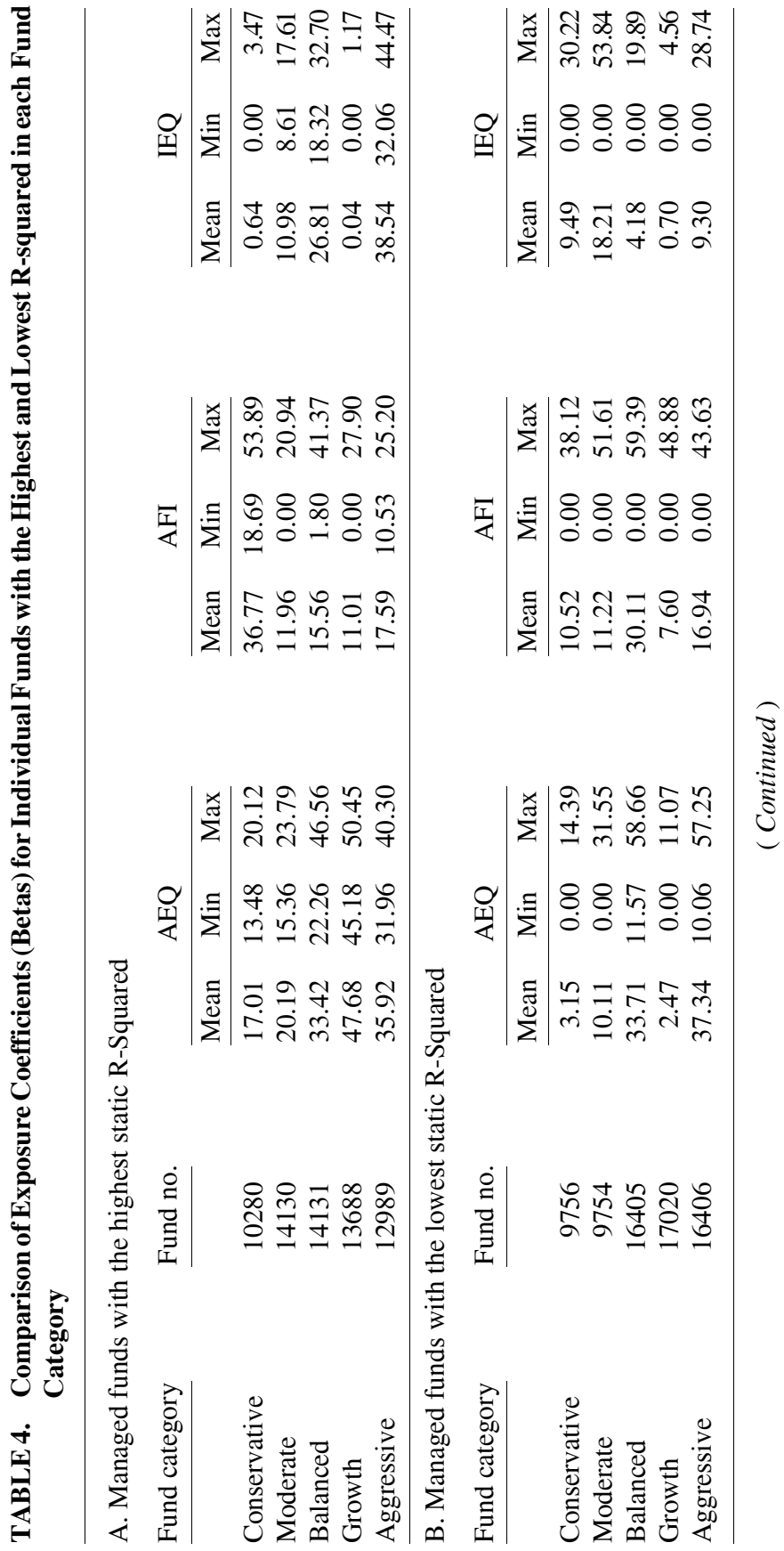




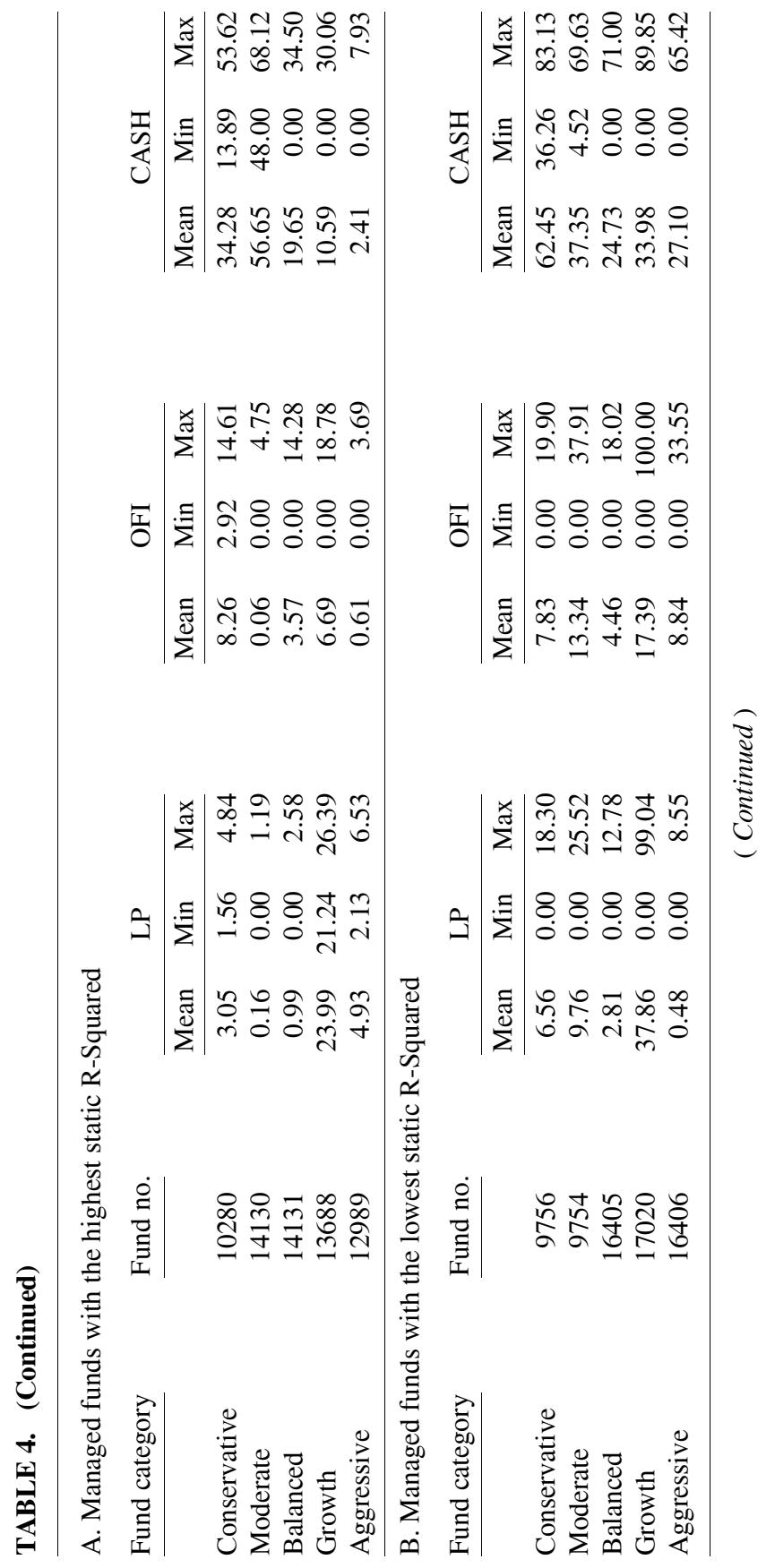




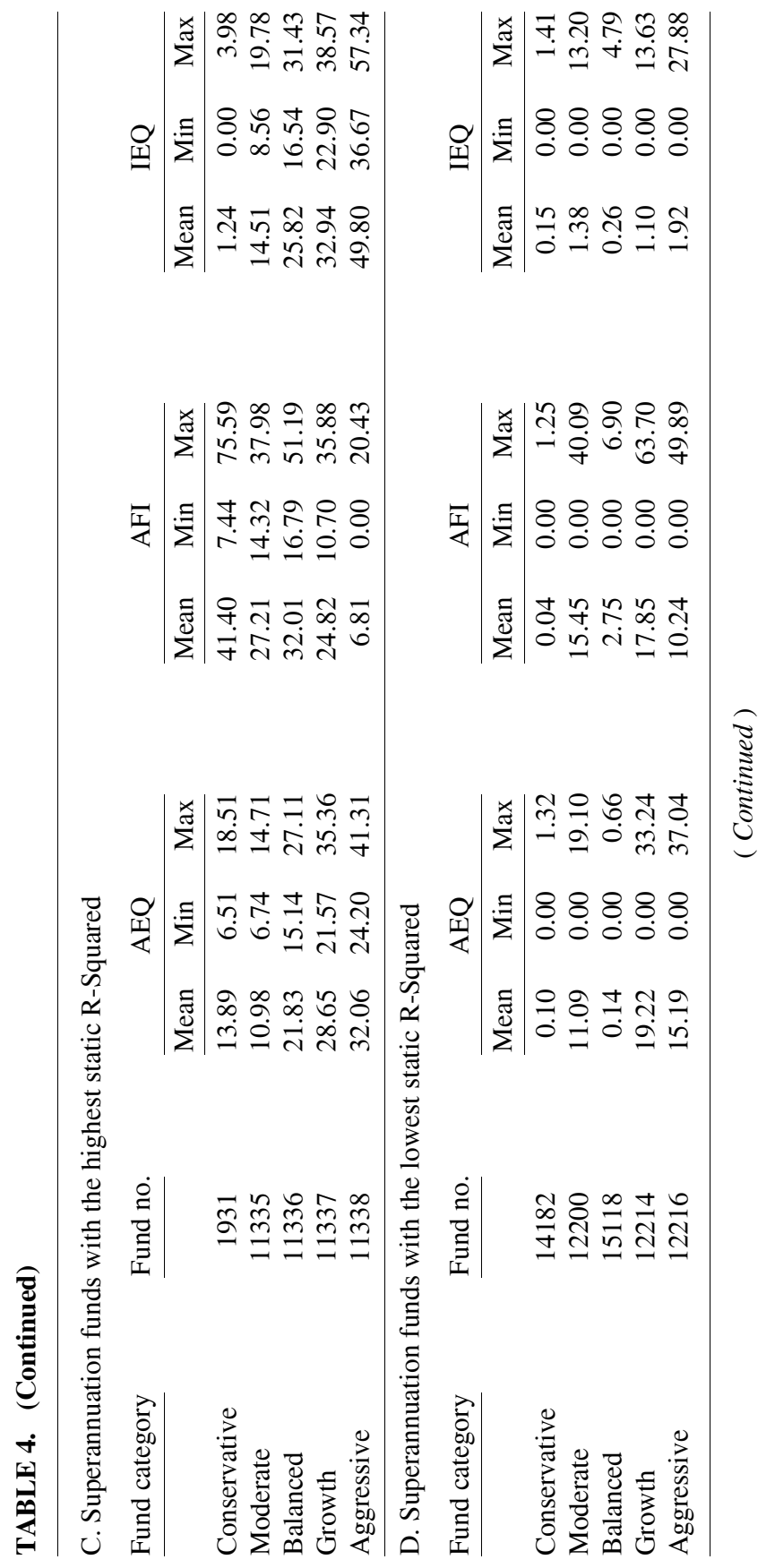




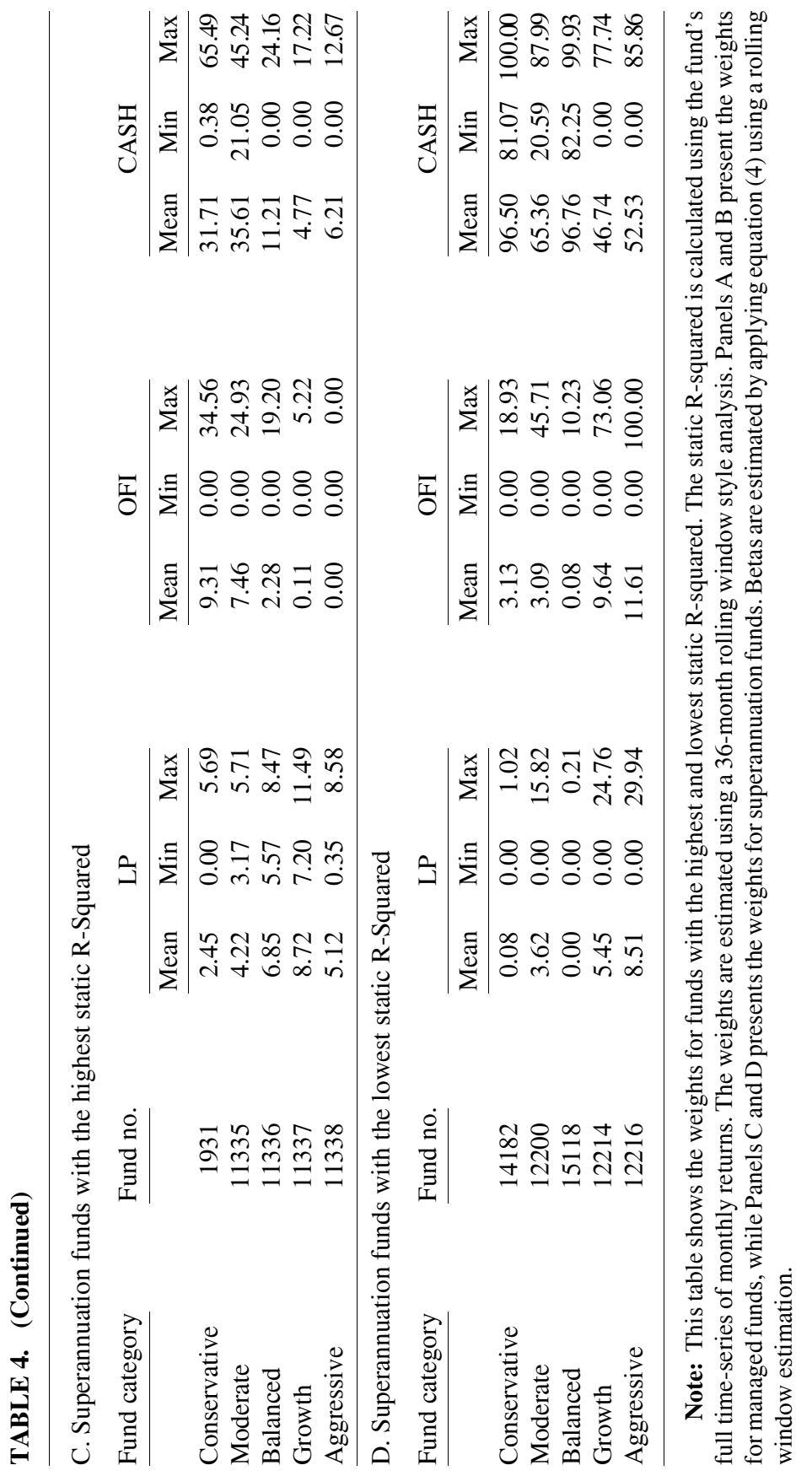


A. Multi-sector Conservative Managed Funds
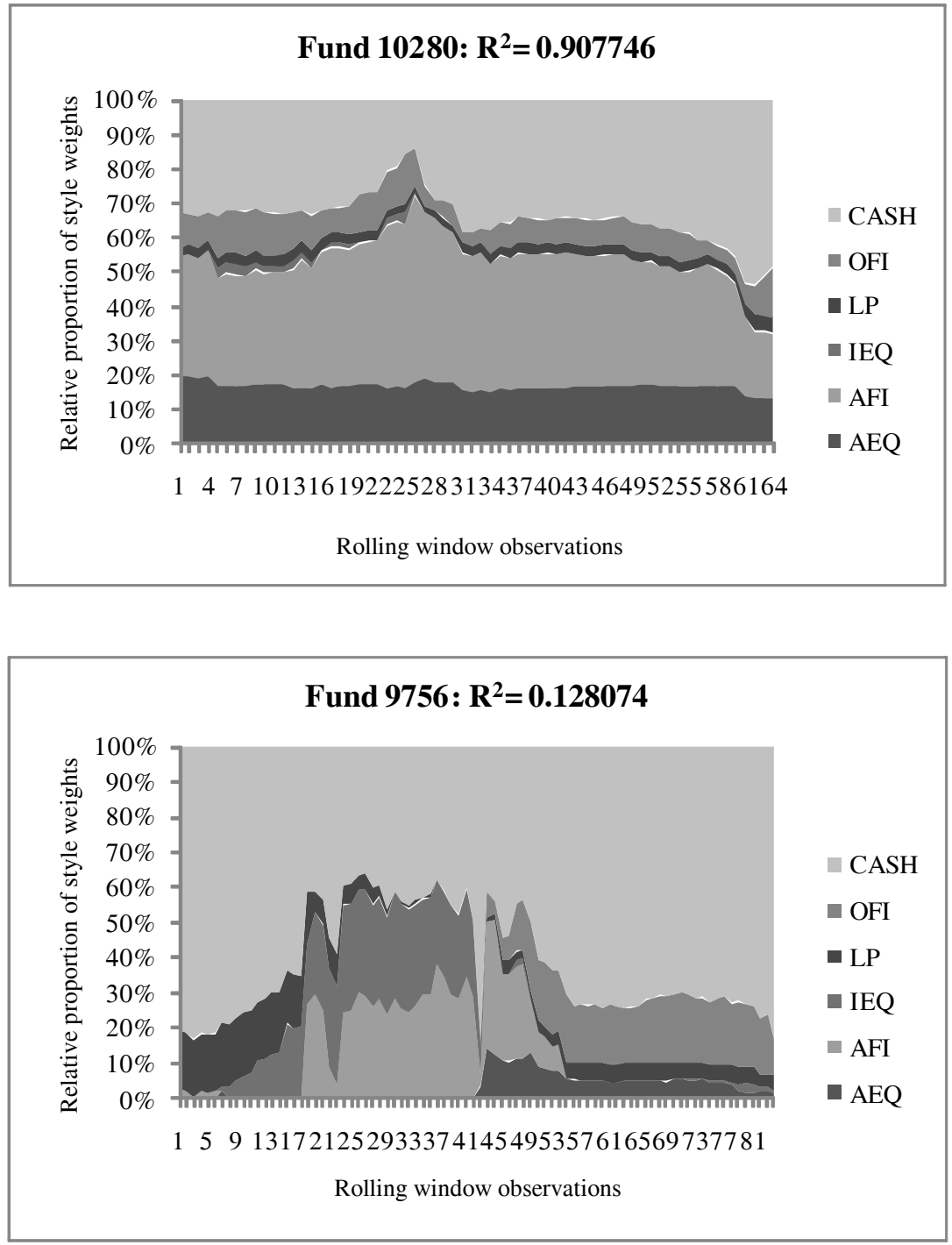
B. Multi-sector Balanced Managed Funds
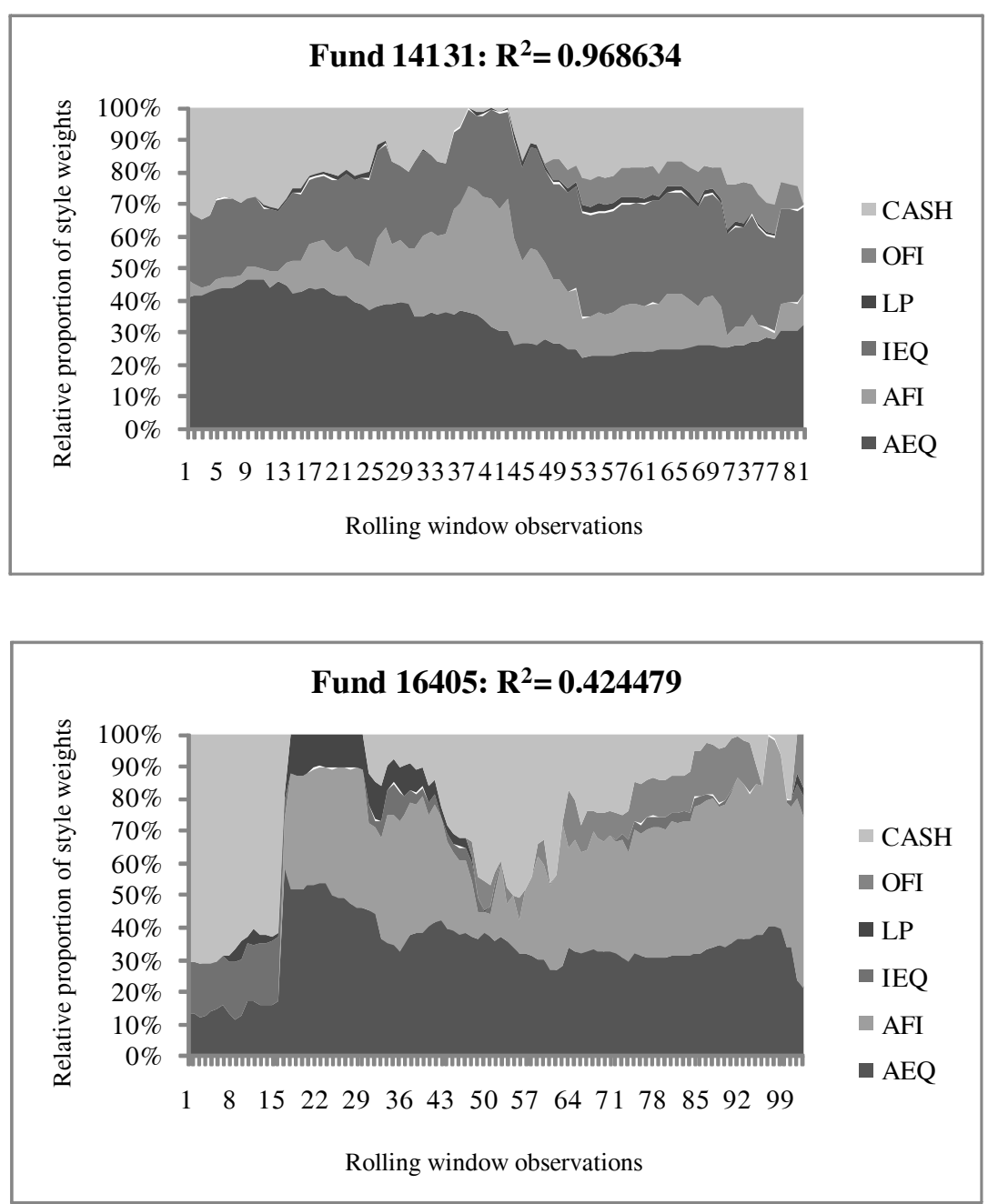
C. Multi-sectorAggressive Managed Funds
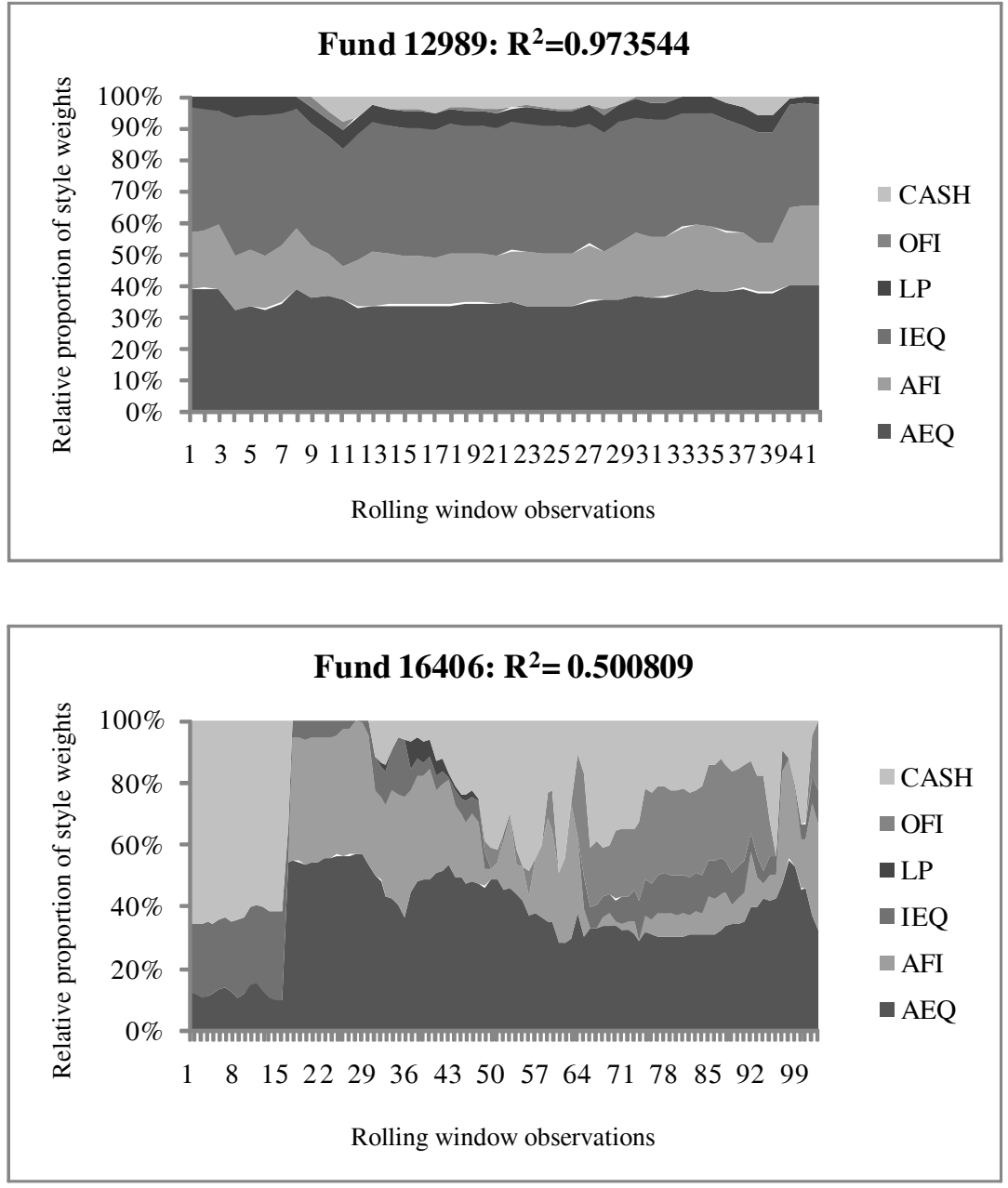
D. Multi-sector Conservative Superannuation Funds
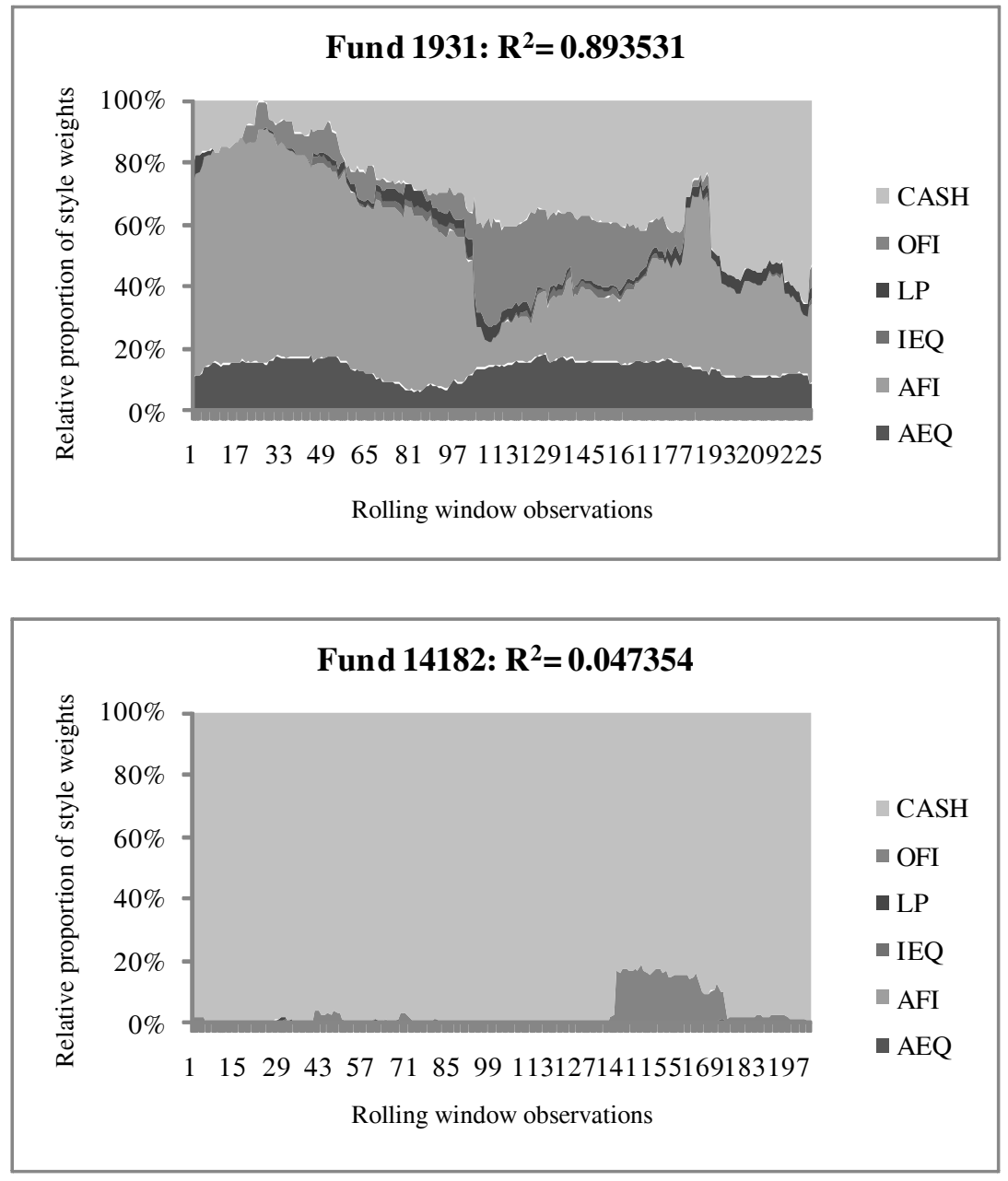
E. Multi-sector Balanced Superannuation Funds
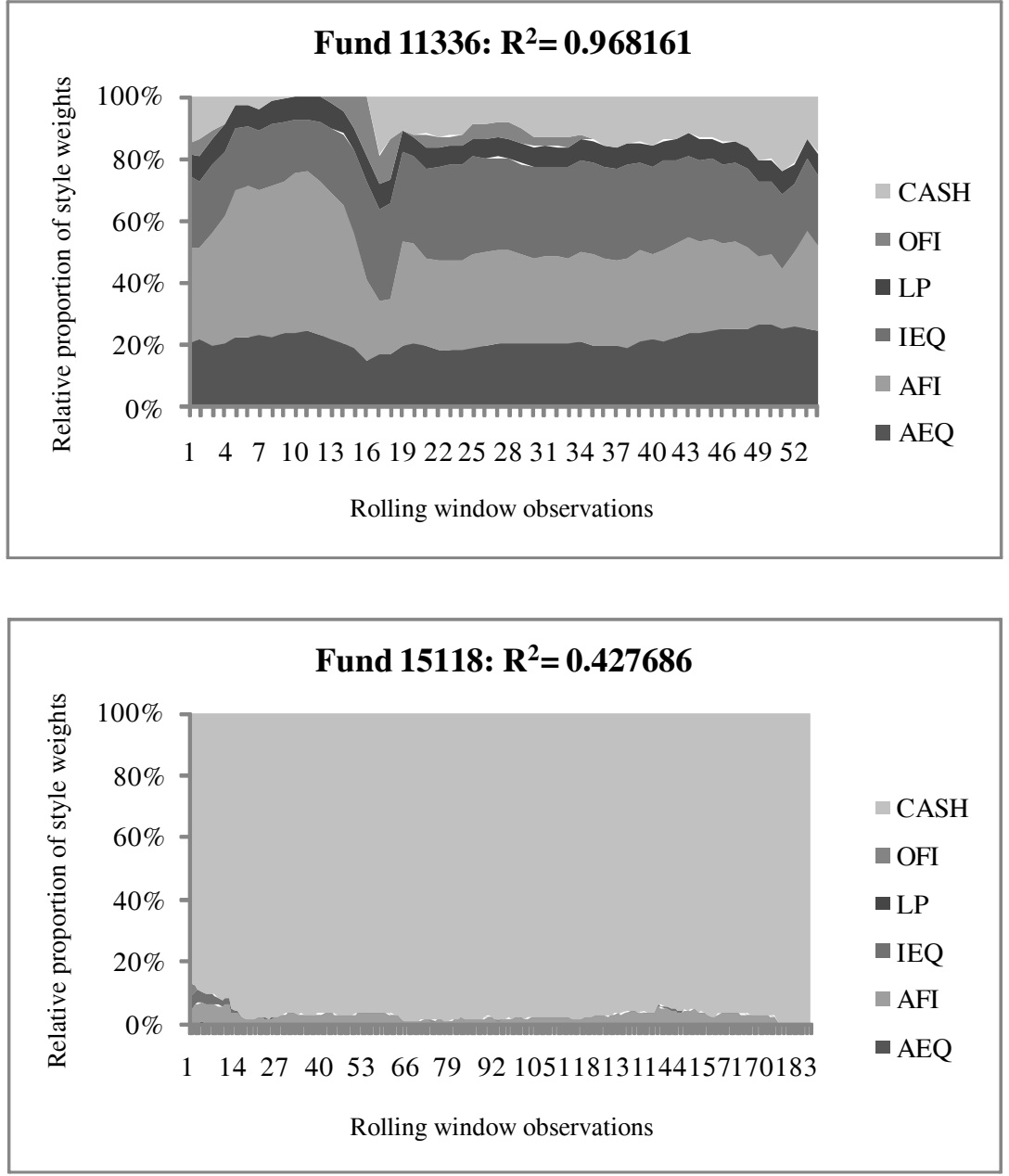
F. Multi-sector Aggressive Superannuation Funds
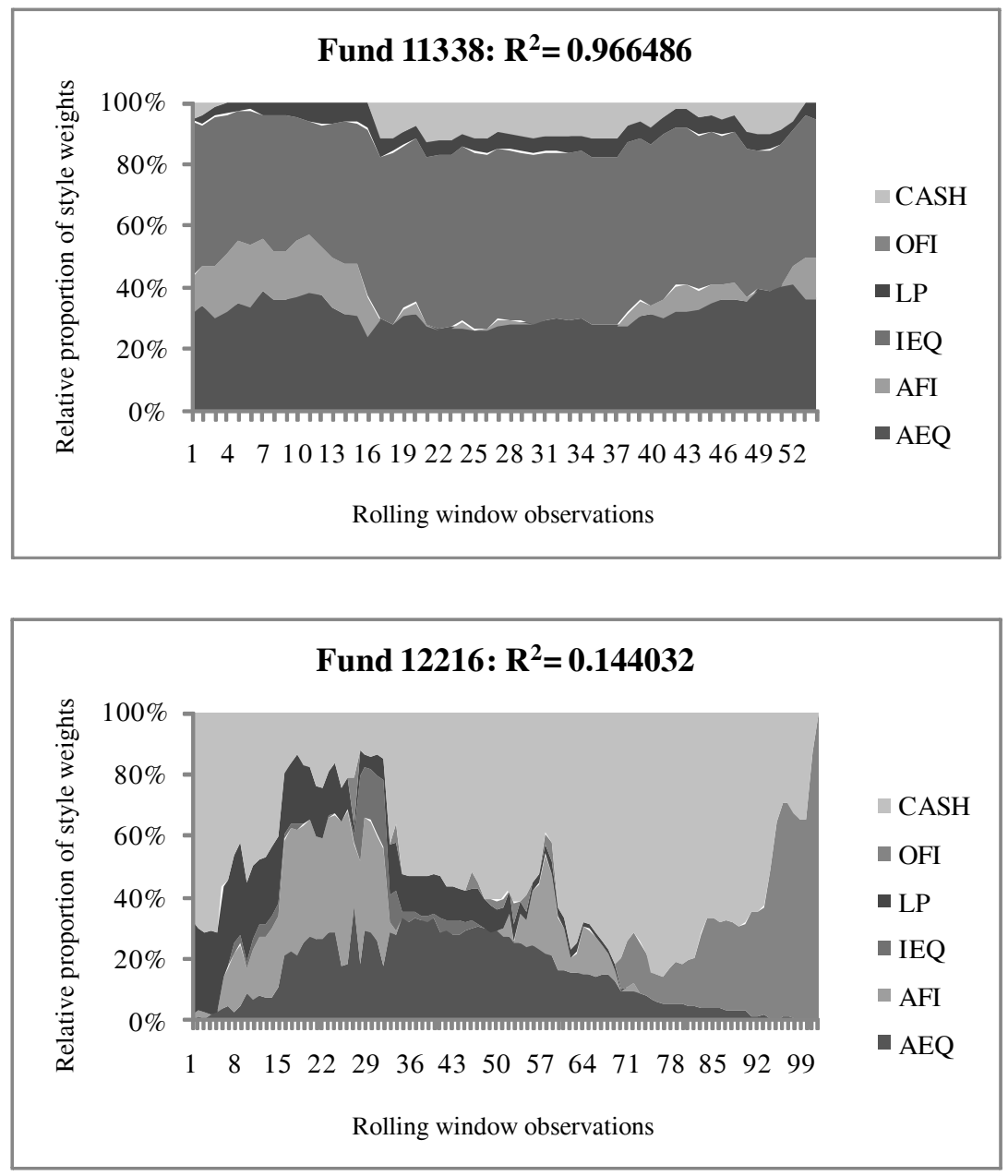

FIGURE 1.- Change in Style Weights over Time for Illustrative Funds

Note: This figure shows two funds from each category with the highest and the lowest static $\mathrm{R}$-squared value, respectively, i.e. the R-squared value obtained from a static (non-rolling window) regression. The changes in style weights over time estimated under the rolling window analysis are plotted. 
benchmarks, as there is clear evidence of frequent portfolio reconstruction, which results in a volatile set of exposure coefficients (Panels A, B and C). For superannuation funds, this pattern is only present in the aggressive category (Panel F). For the remaining two categories, namely conservative (Panel D) and balanced (Panel E), funds with low R-squareds have a high concentration in a single asset class. While this is evidence of low explanatory power for the other asset classes, it does not necessarily suggest inadequate style benchmarks. The reason is that these asset classes have worked very well in explaining the returns of other funds in the same category (such as funds "1931" and "11336"). In sum, the results show that funds that are under the same classification can have substantial differences in investment style.

\section{Forecasting Ability}

Table 5 reports the Mean Absolute Deviation (MAD) and the Mean Squared Deviation (MSD), which compare the predicted fund returns with the realised fund returns using 24-, 36- and 48-month rolling estimation windows. It is observed that the more aggressive the fund style, the greater the MAD and MSD. That is, the MAD and MSD increase monotonically from the conservative fund class to the aggressive fund class. This is evident in both managed funds and superannuation funds suggesting that forecasting ability varies when applied to funds with different styles and the RBSA method works better when predicting fund returns in the less risky fund categories. Additionally, the forecast errors are generally higher for superannuation funds (particularly for the more risky categories), which indicates that the model provides a better prediction for managed funds compared to superannuation funds.

\section{E. Alpha Estimation and Abnormal Performance}

Table 6 reports the tracking error (alpha) and the Sharpe ratio across the five categories for managed and superannuation funds. The tracking error is calculated by averaging the time-series of alpha estimates for each fund obtained from the rolling window regressions, where the rolling window is 24,36 and 48 months in turn. The values reported in the table are the cross-sectional averages within each fund group. As mentioned in section IV, part $C$, the tracking error is a measure of 
TABLE 5. Comparison of Style Prediction Methods

A. Managed Funds

\begin{tabular}{|c|c|c|c|c|c|c|}
\hline \multirow[b]{3}{*}{ Fund category } & \multicolumn{3}{|c|}{ MAD } & \multicolumn{3}{|c|}{ MSD } \\
\hline & \multicolumn{3}{|c|}{ Months in rolling window } & \multicolumn{3}{|c|}{ Months in rolling window } \\
\hline & 24 & 36 & 48 & 24 & 36 & 48 \\
\hline Conservative & 0.313 & 0.311 & 0.304 & 0.00278 & 0.00276 & 0.00231 \\
\hline Moderate & 0.361 & 0.360 & 0.350 & 0.00322 & 0.00322 & 0.00281 \\
\hline Balanced & 0.523 & 0.517 & 0.506 & 0.00663 & 0.00647 & 0.00611 \\
\hline Growth & 0.635 & 0.627 & 0.611 & 0.00820 & 0.00797 & 0.00742 \\
\hline Aggressive & 0.746 & 0.731 & 0.713 & 0.01107 & 0.01053 & 0.00994 \\
\hline Total sample & 0.556 & 0.548 & 0.535 & 0.00699 & 0.00678 & 0.00629 \\
\hline
\end{tabular}

B. Superannuation Funds

\begin{tabular}{|c|c|c|c|c|c|c|}
\hline \multirow[b]{3}{*}{ Fund category } & \multicolumn{3}{|c|}{ MAD } & \multicolumn{3}{|c|}{ MSD } \\
\hline & \multicolumn{3}{|c|}{$\overline{\text { Months in rolling window }}$} & \multicolumn{3}{|c|}{ Months in rolling window } \\
\hline & 24 & 36 & 48 & 24 & 36 & 48 \\
\hline Conservative & 0.318 & 0.309 & 0.291 & 0.00267 & 0.00235 & 0.00200 \\
\hline Moderate & 0.364 & 0.368 & 0.367 & 0.00291 & 0.00298 & 0.00291 \\
\hline Balanced & 0.574 & 0.573 & 0.579 & 0.00817 & 0.00861 & 0.00934 \\
\hline Growth & 0.717 & 0.716 & 0.697 & 0.01054 & 0.01067 & 0.00988 \\
\hline Aggressive & 0.820 & 0.815 & 0.810 & 0.01431 & 0.01401 & 0.01383 \\
\hline Total sample & 0.611 & 0.610 & 0.602 & 0.00866 & 0.00875 & 0.00850 \\
\hline
\end{tabular}

Note: This table reports the mean absolute deviation (MAD) and mean squared deviation (MSD) of the style exposures for different fund categories from the 24-, 36-, and 48-month rolling window estimations. The MAD and MSD quantify the difference between the realised return of the fund and the predicted style times the realised index returns. Average values are reported as a percentage. Panel A reports the MAD and MSD for managed funds, while Panel $B$ reports the same information for superannuation funds.

goodness of fit within sample.

The findings in Panel A for managed funds suggest that riskier funds tend to have larger tracking errors (in absolute value). Specifically, with the exception of the aggressive fund class for the 24-month rolling window, there is a monotonic increase in the absolute value of the tracking errors as the riskiness of the fund class increases. However, there is no clear pattern in the alphas in the superannuation funds in Panel B. In addition, the tracking errors are generally larger (smaller) in absolute value for superannuation funds compared with managed funds for less (more) risky fund groups. With the exception of the lack of a trend in the tracking errors across the superannuation fund classes, the 
results in this table support the earlier findings in table 5, as the MAD and the MSD can be regarded as measures of goodness of fit out of sample. The combined findings suggest that if the asset classes have stronger explanatory power within sample, then this will result in higher out-of-sample predictability.

Ter Horst et al. (2004) argue that when the positivity constraint is imposed and one of the asset classes is a risk-free deposit, then the tracking error (alpha) coincides with the Jensen alpha. These two conditions are met in the sample. However, Ter Horst et al. (2004) also note that alpha should not be used alone when assessing fund performance relative to the benchmark because $\operatorname{Var}\left(\varepsilon_{t}\right)$ is not assumed to be zero. Therefore, researchers should use alpha together with the Sharpe ratio to infer if extra risk is taken in order to earn higher returns.

It is observed that the average alphas for all fund categories are significantly negative, which indicates lower returns generated by the funds compared to the benchmarks. This finding is reinforced by the negative Sharpe ratio for all fund categories. Managed funds, on average, exhibit higher (less negative) alphas and Sharpe ratios than superannuation funds in three of the fund categories: conservative, moderate and balanced. This indicates that although both managed and superannuation funds generate lower returns compared to their benchmarks, managed funds underperform to a lesser extent in these three relatively less risky categories compared to superannuation funds. The better performance of managed fund managers can be attributed to either better selectivity skills or because managed funds charge lower fees. ${ }^{9}$

As for the growth category, while superannuation funds exhibit higher alphas, their Sharpe ratio is lower. Finally, for the aggressive category, superannuation funds outperform managed funds, as their alpha is higher and this is also accompanied by a higher Sharpe ratio. A potential reason is as follows: while managed fund managers generally tend to allocate a higher proportion of their portfolio to risky asset classes, this effect is stronger in the aggressive category. Since the sample includes the financial crisis period where risky assets performed very poorly, a fund which allocates a large portion of their portfolio to high risk asset classes is likely to be a poor performer.

9. As mentioned in section II, part $A$, the structure of superannuation funds is more complicated and hence, they generate higher fees compared to managed funds. 
TABLE 6. Comparison of Selectivity Coefficients (Alphas) and Sharpe Ratios

A. Managed Funds

\begin{tabular}{|c|c|c|c|c|c|c|c|}
\hline \multirow[t]{2}{*}{ Fund category } & \multicolumn{2}{|c|}{24 months } & \multicolumn{2}{|c|}{36 months } & \multicolumn{2}{|c|}{48 months } & \multirow[b]{2}{*}{ Sharpe Ratio } \\
\hline & Alpha & t-stat & Alpha & t-stat & Alpha & t-stat & \\
\hline Conservative & $-1.013 *$ & -6.35 & $-1.104 *$ & -6.76 & $-1.143 *$ & -6.80 & -2.169 \\
\hline Moderate & $-1.030 *$ & -11.40 & $-1.112 *$ & -12.13 & $-1.166^{*}$ & -12.84 & -1.145 \\
\hline Balanced & $-1.208 *$ & -6.90 & $-1.264 *$ & -6.67 & $-1.280 *$ & -6.41 & -1.052 \\
\hline Growth & $-1.703^{*}$ & -17.66 & $-1.729 *$ & -18.10 & $-1.714^{*}$ & -18.42 & -1.259 \\
\hline Aggressive & $-1.657^{*}$ & -13.80 & $-1.746^{*}$ & -14.22 & $-1.732 *$ & -13.70 & -1.924 \\
\hline Total sample & $-1.429 *$ & -24.64 & $-1.484 *$ & -25.14 & $-1.493 *$ & -25.23 & -1.352 \\
\hline
\end{tabular}

B. Superannuation Funds

\begin{tabular}{|c|c|c|c|c|c|c|c|}
\hline \multirow[t]{2}{*}{ Fund category } & \multicolumn{2}{|c|}{24 months } & \multicolumn{2}{|c|}{36 months } & \multicolumn{2}{|c|}{48 months } & \multirow[b]{2}{*}{ Sharpe Ratio } \\
\hline & Alpha & t-stat & Alpha & t-stat & Alpha & t-stat & \\
\hline Conservative & $-1.342 *$ & -7.71 & $-1.419^{*}$ & -8.21 & $-1.454 *$ & -8.36 & -13.178 \\
\hline Moderate & $-1.417 *$ & -14.52 & $-1.475^{*}$ & -14.71 & $-1.568 *$ & -15.00 & -6.230 \\
\hline Balanced & $-1.203 *$ & -11.87 & $-1.320^{*}$ & -13.39 & $-1.439 *$ & -14.55 & -4.127 \\
\hline Growth & $-1.595 *$ & -15.31 & $-1.630^{*}$ & -15.62 & $-1.683 *$ & -16.53 & -2.525 \\
\hline Aggressive & $-1.375^{*}$ & -7.65 & $-1.392 *$ & -8.34 & $-1.371^{*}$ & -7.91 & -1.236 \\
\hline Total sample & $-1.438 *$ & -24.82 & $-1.493 *$ & -26.17 & $-1.555^{*}$ & -27.24 & -3.991 \\
\hline
\end{tabular}

Note: This table shows the alphas estimated by applying equation (4) using the 24-, 36and 48-month rolling window estimations, and the Sharpe ratios. The average monthly alphas are annualised by multiplying by 12 and average values are reported as a percentage. Panel A reports the results for managed funds, while Panel B reports the same information for superannuation funds. *Indicates significance at the 1 per cent level.

\section{V.Summary and Conclusions}

Style analysis, especially RBSA, has been widely used in practice as well as in academic research for analysing fund returns. This technique is particularly useful when the asset classes are well-defined. The paper applies RBSA to compare the investment strategies adopted by Australian managed and superannuation fund managers. The results demonstrate that the riskier fund classes are more exposed to the riskier benchmarks. Moreover, there is some evidence of superannuation fund managers preferring overseas fixed income securities as opposed to their corresponding domestic products, a finding which warrants further investigation in future research. With regard to performance, managed funds outperform superannuation funds in most categories, particularly 
the less risky ones, while superannuation funds only outperform in the aggressive class. This can be attributed to managed fund managers having better selectivity skills or charging lower fees. In summary, we conclude that differences in institutional and legal frameworks lead managers to invest differently, which is evidenced by superannuation fund managers adopting a more conservative strategy compared to managed funds despite having much longer investment horizons.

Accepted by: Prof. P. Theodossiou, Editor-in-Chief, December 2012

\section{References}

Alexakis, P., and Tsolas, I. 2011. Appraisal of mutual equity fund performance using data envelopment analysis. Multinational Finance Journal 15: 273-296.

Allen, N.; Phoon, K.F.; Watson, J.; and Wickramanayake, J. 2010. Investing into the Abyss: the continued misclassification of multi-sector managed funds. Working Paper. Singapore Management University.

Atkinson, S.M., and Choi, Y.K.2001. Investment style of portfolio management: Excel applications. Journal of Applied Finance 11: 61-69.

Bird, R.; Chin, H.; and McCrae, M. 1983. The performance of Australian superannuation funds. Australian Journal of Management 8: 49-69.

Bodson, L.; Coen, A.; and Hubner, G. 2010. Dynamic hedge fund style analysis with errors-in-variables. Journal of Financial Research 33: 201-221.

Buetow, G.W.; Johnson, R.; and Runkle, D. 2000. The inconsistency of return-based style analysis. Journal of Portfolio Management 26: 61-77.

Chan, L.C.; Chen, H.L.; and Lakonishok, J. 2002. On mutual fund investment styles. Review of Financial Studies 15: 1407-1437.

Charitou, A.; Makris, A.; and Nishiotis, G.P. 2006. Closed-end country funds and international diversification. Multinational Finance Journal 10: 251-276.

Del Guercio, D., and Tkac, P.A. 2002. The determinants of the flow of funds of managed portfolios: mutual funds vs. pension funds. Journal of Financial and Quantitative Analysis 37: 523-557.

Domian, D.L., and Reichenstein, W. 2009. Returns-based style analysis of convertible bond funds. Journal of Fixed Income 18: 52-64.

Dor, A.B., and Jagannathan, R. 2002. Understanding mutual fund and hedge fund styles using return based style analysis. NBER working paper series.

Dunn, P.; Francis, S.; and Hall, J. 2009. Leveraged superannuation. Accounting and Finance 49: 509-529.

Faff, R.W.; Gallagher D.R.; and Wu, R. 2005. Tactical asset allocation: Australian Evidence. Australian Journal of Management 30: 261-282. 
Ferson, W.E., and Schadt, R.W. 1996. Measuring fund strategy and performance in changing economic conditions. Journal of Finance 51: 425-461.

Gerrans, P.; Kristoffersen, I.; and Clark-Murphy, M. 2004. The behaviour of socially responsible investments as financial assets. Australian Accounting Review 14: 10-20.

Grinblatt, M.; Titman, S.; and Wermers, R. 1995. Momentum investment strategies, portfolio performance, and herding: A study of mutual fund behaviour. American Economic Review 85: 1088-1105.

Hallahan, T., and Faff, R.W. 1999. An examination of Australian equity trusts for selectivity and market timing performance. Journal of Multinational Financial Management 9: 387-402.

Holmes, K.A., and Faff, R.W. 2000. Cross sectional determinants of managed funds risk and performance: Evidence for Australian equity trusts. Accounting, Accountability and Performance 6: 55-75.

Holmes, K.A., and Faff, R.W. 2007. Style drift, fund flow and fund performance: new cross-sectional evidence. Financial Services Review 16: 55-71.

Holmes, K.A., and Faff, R.W. 2008. Style drift and fund performance in up and down markets: Australian evidence. Applied Financial Economic Letters 4: 395-387.

Jensen, M. 1968. The performance of mutual funds in the period 1945-1964. Journal of Finance 23: 389-416.

Kim, M.; Shukla, R.; and Tomas, M. 2000. Mutual fund objective misclassification. Journal of Economics and Business 52: 309-323.

Lucas, L., and Riepe, M.1996. The role of return-based style analysis: Understanding, implementing, and interpreting the technique. Working paper. Ibbotson Associates.

Papadamou, S., and Siriopoulos, C. 2004. American equity mutual funds in European markets: hot hands phenomenon and style analysis. International Journal of Finance and Economics 9: 85-97.

Phoon, K.F.; Watson, J.; and Wickramanayake, J. 2008. Further evidence on the approximation of confidence intervals for Sharpe style weights: the case of Australian listed managed funds. Journal of Investment Management and Financial Innovations 5: 57-72.

Robson, G.N. 1986. The investment performance of unit trusts and mutual funds in Australia for the period 1969-1978. Accounting and Finance 26: 55-79.

Sharpe, W.F. 1988. Determining a fund's effective asset mix. Investment Management Review 2: 7-19.

Sharpe, W.F. 1992. Asset allocation: Management style and performance measurement. Journal of Portfolio Management 18: 7-19.

Sinclair, N. 1990. Market timing ability of pooled superannuation funds January 1981 to December 1987. Accounting and Finance 30: 51-65. 
Ter Horst, J.; Nijman, T.E.; and de Roon, F.A. 2004. Evaluating style analysis. Journal of Empirical Finance 11: 29-53.

Xiong, J.X.; Ibbotson, R.G.; Idzorek, T.M.; and Chen, P. 2010. The equal importance of asset allocation and active management. Financial Analysts Journal 66: 22-30.

Vos, E.; Brown, P.; and Christie. 1995. A test of persistence in the performance of New Zealand and Australian equity mutual funds. Accounting Research Journal 8: 19-34. 